Published in final edited form as:

ACS Synth Biol. 2019 September 20; 8(9): 2017-2024. doi:10.1021/acssynbio.9b00047.

\title{
Employing 25-Residue Docking Motifs from Modular Polyketide Synthases as Orthogonal Protein Connectors
}

\author{
Jessica L. Meinke ${ }^{\dagger, \ddagger}$, Anna J. Simon ${ }^{\dagger, \S}$, Drew T. Wagner ${ }^{\dagger, \ddagger}$, Barrett R. Morrow ${ }^{\dagger}$, Shaochen \\ You $^{\dagger}$, Andrew D. Ellington ${ }^{\dagger, \ddagger}, \S$, Adrian T. Keatinge-Clay ${ }^{*}, \dagger, \neq$ \\ tDepartment of Molecular Biosciences, The University of Texas at Austin, Austin, Texas 78712, \\ United States \\ \#Institute for Cellular and Molecular Biology, The University of Texas at Austin, Austin, Texas \\ 78712, United States \\ $\S$ Center for Systems and Synthetic Biology, The University of Texas at Austin, Austin, Texas \\ 78712, United States
}

\begin{abstract}
The proteins of trans-acyltransferase modular polyketide synthases (PKSs) self-organize into assembly lines, enabling the multienzyme biosynthesis of complex organic molecules. Docking domains comprised of $\sim 25$ residues at the $\mathrm{C}$ - and $\mathrm{N}$-termini of these polypeptides ( ${ }^{\mathrm{C}} \mathrm{DDs}$ and ${ }^{N}$ DDs) help drive this association through the formation of four-helix bundles. Molecular connectors like these are desired in synthetic contexts, such as artificial biocatalytic systems and biomaterials, to orthogonally join proteins. Here, the ability of six ${ }^{\mathrm{C}} \mathrm{DD} /{ }^{\mathrm{N}} \mathrm{DD}$ pairs to link nonPKS proteins is examined using green fluorescent protein (GFP) variants. As observed through size-exclusion chromatography and Förster resonance energy transfer (FRET), matched but not mismatched pairs of Venus $+{ }^{\mathrm{C}} \mathrm{DD}$ and ${ }^{\mathrm{N}} \mathrm{DD}+\mathrm{mTurquoise} 2$ fusion proteins associate with low micromolar affinities.
\end{abstract}

\section{Graphical Abstract}

\footnotetext{
*Corresponding Author: adriankc@utexas.edu. Author Contributions

J.L.M., A.J.S., and D.T.W. are cofirst authors. A.J.S., D.T.W., A.D.E., and A.T.K. conceived the project. A.J.S. and D.T.W. designed the Venus $+{ }_{\mathrm{DD}}$ and ${ }^{\mathrm{N}} \mathrm{DD}+$ Turquoise 2 constructs. J.L.M., A.J.S., D.T.W., B.M., and S.Y. expressed and purified the proteins. J.L.M. and D.T.W. performed the size-exclusion chromatography and ran the SDS-PAGE gels. A.J.S. acquired and analyzed the FRET measurements. J.L.M. and A.J.S. wrote the paper with input from A.D.E. and A.T.K.

Supporting Information

The Supporting Information is available free of charge on the ACS Publications website at DOI: 10.1021/acssynbio.9b00047. Primer sequences, size-exclusion traces, SDS-PAGE analysis, data processing methods, fluorescence spectra, FRET efficiency plots, and titrations at differing $\mathrm{pH}$ and salt concentrations (PDF)

The authors declare no competing financial interest.
} 


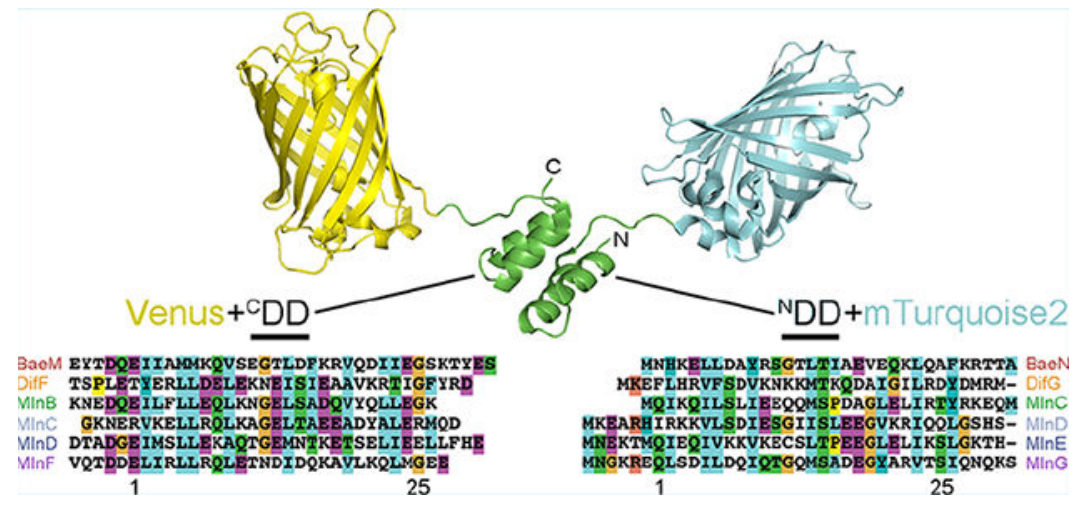

\section{Keywords}

docking domain; four-helix bundle; orthogonal connectors; polyketide synthase; fluorescent proteins; FRET

Engineering macromolecular complexes that assemble into specific structures has been a long-standing goal in materials science, chemical engineering, and synthetic biology. ${ }^{1}$ These assemblies could facilitate such processes as the synthesis of medicines, the delivery of drugs, and the transport of energy. To help engineer these complexes, researchers have harnessed modular connectors such as oligonucleotides, ${ }^{2-4}$ metal-binding domains, ${ }^{5-7}$ and leucine zippers. ${ }^{8,9}$ However, these connectors each have their limitations: connecting proteins with oligonucleotides can be cumbersome, metalbinding domains have limited orthogonality, and leucine zippers require the interaction of long a-helices that can geometrically constrain the bound domains.

A promising yet largely unexplored class of connectors are the recently discovered fourhelix bundle docking domains that commonly join polypeptides within the transacyltransferase modular polyketide synthases (trans-AT PKSs)(Figure 1). ${ }^{10-13}$ The enzymes that reside in these polypeptides mediate the synthesis of polyketide natural products. ${ }^{14-17}$ For groups of these enzymes known as modules (the calyculin assembly line contains thirtythree), ${ }^{18}$ to correctly elongate growing intermediates, the polypeptides of the assembly line need to be precisely ordered.

While the polypeptides of the cis-AT PKSs, ${ }^{16,17,19}$ such as the erythromycin synthase, rely on homodimeric docking motifs $\mathrm{C}$-terminal to the acyl carrier protein (ACP) domain and $\mathrm{N}$ terminal to the ketosynthase (KS) domain, ${ }^{20-22}$ the polypeptides of trans-AT PKSs are connected through split domains at various locations within the module. These domains can be enzymes such as ketoreductases (KRs) or dehydratases (DHs); however, the most common split domain is a four-helix bundle formed by two helices at the C-terminus of an upstream polypeptide and two helices at the $\mathrm{N}$-terminus of a downstream polypeptide (the $\mathrm{C}$ - and $\mathrm{N}$-terminal portions of the docking domain are referred to as ${ }^{\mathrm{C}} \mathrm{DD}$ and $\left.{ }^{\mathrm{N}} \mathrm{DD}\right) \cdot{ }^{13 \mathrm{C}} \mathrm{DD}$ and ${ }^{\mathrm{N}} \mathrm{DD}$ have been shown to interact in a pseudosymmetric manner with low micromolar affinity. ${ }^{12,13}$ While the docking domains of cis-AT and trans-AT PKSs both naturally operate 
in the context of homodimers, only those of trans-AT PKSs are functional as monomers and thus suited for (but not limited to) connecting monomeric proteins.

Cognate ${ }^{\mathrm{C}} \mathrm{DD} /{ }^{\mathrm{N}} \mathrm{DD}$ pairs within Bacillus amyloliquefaciens FZB42 (a.k.a. Bacillus velezensis FZB42) help mediate the self-organization of the assembly lines that produce the polyketides bacillaene, difficidin, and macrolactin. ${ }^{14}$ In a previous study from our group, the association of portions of trans-AT PKS polypeptides containing cognate ${ }^{\mathrm{C}}$ DDs and ${ }^{\mathrm{N}}$ DDs was observed. ${ }^{13}$ Through swapping the ${ }^{\mathrm{C}} \mathrm{DD}$ and ${ }^{\mathrm{N}} \mathrm{DD}$ motifs new connections between PKS enzymes could be engineered. While these experiments indicated that ${ }^{\mathrm{C}} \mathrm{DD}$ and ${ }^{\mathrm{N}} \mathrm{DD}$ are portable between the polypeptides of trans-AT assembly lines, their ability to connect non-PKS proteins was not investigated.

Here, we report the use of $B$. amyloliquefaciens ${ }^{\mathrm{C}} \mathrm{DD} / \mathrm{N} \mathrm{DD}$ pairs to orthogonally connect non-PKS proteins, demonstrating their ability to mediate the association of the monomeric green fluorescent protein (GFP) variants Venus and mTurquoise2. ${ }^{23,24} \mathrm{C}$ DD and ${ }^{\mathrm{N}} \mathrm{DD}$ motifs from the bacillaene, difficidin, and macrolactin assembly lines of $B$. amyloliquefaciens FZB42 appended to the termini of Venus and mTurquoise 2 enabled orthogonal connectivities with low micromolar affinities. The association of Venus $+{ }^{\mathrm{C}} \mathrm{DD}$ and ${ }^{\mathrm{N}} \mathrm{DD}$ +mTurquoise 2 cognates, visualized by size-exclusion chromatography and measured using Förster resonance energy transfer (FRET), demonstrates the utility of these docking domains in generating engineered complexes.

\section{RESULTS AND DISCUSSION}

Four helix-bundle docking domains connect polypeptides in each of the three trans-AT PKSs from B. amyloliquefaciens FZB42: once in the bacillaene assembly line ( ${ }^{C} \mathrm{DD}_{\mathrm{BaeM}} /$ ${ }^{\mathrm{N}} \mathrm{DD}_{\mathrm{BaeN}}$ for polypeptides BaeM/BaeN), once in the difficidin assembly line ( ${ }^{\mathrm{C}} \mathrm{DD}_{\mathrm{DifF}} /$ ${ }^{\mathrm{N}} \mathrm{DD}_{\text {DifG }}$ for polypeptides DifF/DifG), and four times in the macrolactin assembly line $\left({ }^{\mathrm{C}} \mathrm{DD}_{\mathrm{MlnB}} /{ }^{\mathrm{N}} \mathrm{DD} \mathrm{MlnC}_{\mathrm{C}}\right.$ for polypeptides MlnB/MlnC, ${ }^{\mathrm{N}} \mathrm{DD}_{\mathrm{MlnC}} /{ }^{\mathrm{N}} \mathrm{DD} \mathrm{MlnD}_{\mathrm{n}}$ for polypeptides MlnC/MlnD, ${ }^{\mathrm{N}} \mathrm{DD}_{\mathrm{MlnD}} /{ }^{\mathrm{N}} \mathrm{DD} \mathrm{MlnE}_{\text {f }}$ for polypeptides MlnD/MlnE, and ${ }^{\mathrm{N}} \mathrm{DD}_{\mathrm{MlnF}}{ }^{\mathrm{N}} \mathrm{DD} \mathrm{MlnG}$ for polypeptides MlnF/MlnG)(Figure 1b). Each of these ${ }^{\mathrm{C}} \mathrm{DD}$ and ${ }^{\mathrm{N}} \mathrm{DD}$ motifs was fused to the yellow GFP variant Venus and the cyan GFP variant mTurquoise2, respectively. ${ }^{23,24}$ Venus ${ }^{\mathrm{C}} \mathrm{DD}$ fusion proteins were engineered by linking the Venus domain and ${ }^{\mathrm{C}} \mathrm{DD}$ motif through a glycine, a serine, and $4-5$ residues that naturally precede the ${ }^{\mathrm{C}} \mathrm{DD}$. Fusion ${ }^{\mathrm{N}} \mathrm{DD}$ +Turquoise 2 proteins were engineered by linking the ${ }^{\mathrm{N}} \mathrm{DD}$ motif and mTurquoise 2 domain with 5-6 residues naturally downstream of ${ }^{\mathrm{N}} \mathrm{DD}$. To minimize interference with ${ }^{\mathrm{C}} \mathrm{DD} /{ }^{\mathrm{N}} \mathrm{DD}$ interactions, vector-encoded hexahistidine purification tags were positioned on the terminus opposite of the docking motif (N-terminal in Venus $+{ }^{\mathrm{C}} \mathrm{DD}$ constructs and $\mathrm{C}$-terminal in ${ }^{\mathrm{N}} \mathrm{DD}$ + mTurquoise2 constructs). The 12 fusion proteins were expressed in Escherichia coli BL21(DE3) from pET28b-derived plasmids and purified. Each construct showed the expected fluorescent properties, with the peak excitation and emission wavelengths at $\sim 510$ and $\sim 530 \mathrm{~nm}$ for the Venus $+{ }^{\mathrm{C}} \mathrm{DD}$ constructs and $\sim 420$ and $\sim 480 \mathrm{~nm}$ for the ${ }^{\mathrm{N}} \mathrm{DD}$ + mTurquoise 2 constructs (Figure S1).

Orthogonal interactions were first observed between Venus $+{ }^{\mathrm{C}} \mathrm{DD}$ and ${ }^{\mathrm{N}} \mathrm{DD}+\mathrm{mTurquoise} 2$ constructs by size-exclusion chromatography (Figures 2 and S2). When loaded individually 
onto a Superdex 200 column, Venus+ ${ }^{\mathrm{C}} \mathrm{DD}$ and ${ }^{\mathrm{N}} \mathrm{DD}+\mathrm{mTurquoise} 2$ constructs elute at $17-18$ $\mathrm{mL}$. However, when loaded together in equimolar amounts, matched pairs of Venus ${ }^{\mathrm{C}} \mathrm{DD}$ and ${ }^{\mathrm{N}} \mathrm{DD}+\mathrm{mTurquoise} 2$ constructs primarily elute earlier, at $\sim 15 \mathrm{~mL}$, indicating the formation of a larger complex (with smaller peaks at $17-18 \mathrm{~mL}$ from residual, uncomplexed protein). The behavior of each Venus $+{ }^{\mathrm{C}} \mathrm{DD}$ construct in the presence of each of the six ${ }^{\mathrm{N}} \mathrm{DD}$ + mTurquoise 2 constructs was also observed through a series of Coomassiestained SDSPAGE gels. These gels indicated that for five of the six pairs tested, only cognate pairs of Venus $+{ }^{C}$ DD and ${ }^{\mathrm{N}} \mathrm{DD}+\mathrm{mT}$ Trquoise 2 interact. For example, while Venus+ ${ }^{\mathrm{C}} \mathrm{DD}_{\mathrm{BaeM}}$ forms a complex with ${ }^{\mathrm{N}} \mathrm{DD}_{\mathrm{BaeN}}+\mathrm{mTurquoise} 2$, it does not form a complex with any of the other ${ }^{\mathrm{N}} \mathrm{DD}+\mathrm{mTurquoise} 2$ constructs (Figure 2c). The other constructs show similar orthogonality, with the exception of Venus $+{ }^{C} D_{M l n B}$, which complexes weakly with the ${ }^{\mathrm{N}} \mathrm{DD}_{\mathrm{MlnD}}$ + mTurquoise2, ${ }^{\mathrm{N}} \mathrm{DD}_{\mathrm{MlnE}}+\mathrm{mTurquoise} 2$, and ${ }^{\mathrm{N}} \mathrm{DD}_{\mathrm{MlnG}}+\mathrm{mTurquoise} 2$ constructs (Figure S3).

Measurements of Förster resonance energy transfer (FRET) between Venus ${ }^{\mathrm{C}} \mathrm{DD}$ and ${ }^{\mathrm{N}} \mathrm{DD}$ + mTurquoise 2 constructs enabled characterization of the concentration-dependent nature of their interactions. FRET is an energy transfer mechanism in which an excited donor fluorophore nonradiatively transfers energy to a nearby acceptor fluorophore and is commonly harnessed to detect bimolecular interactions by fusing interacting proteins or domains of interest to a complementary pair of donor and acceptor fluorescent proteins. ${ }^{25,26}$ Interactions that bring the donor and acceptor into close proximity enable FRET between the donor and acceptor, which results in increased acceptor and decreased donor fluorescence in response to donor excitation. The FRET efficiency $E$ depends on the distance between the acceptor and donor, $r$

$$
E=\frac{1}{1+r^{6} / R_{0} 6}
$$

where $R_{0}$ is the Förster radius, the distance between the acceptor and donor at which FRET efficiency is half its maximum value. In the experimental system described here, Venus and mTurquoise 2 serve as both test proteins to assess the ability of ${ }^{\mathrm{C}} \mathrm{DD} /{ }^{\mathrm{N}} \mathrm{DD}$ pairs to connect non-PKS proteins and as the acceptor/donor FRET pair to enable detection of ${ }^{\mathrm{C}} \mathrm{DD} /{ }^{\mathrm{N}} \mathrm{DD}$ interactions. Because the Förster radius between Venus and mTurquoise2 $(5.8 \mathrm{~nm})^{27}$ is larger than the expected distance between chromophores upon docking domain-mediated connection, the FRET efficiency between ${ }^{\mathrm{C}} \mathrm{DD} /{ }^{\mathrm{N}} \mathrm{DD}$-complexed Venus and mTurquoise2 proteins is expected to be relatively high.

Consistent with the size-exclusion chromatography binding assays, FRET measurements indicated specific, orthogonal interactions between matched Venus $+{ }^{\mathrm{C}} \mathrm{DD}$ and ${ }^{\mathrm{N}} \mathrm{DD}$ + mTurquoise 2 constructs (Figures 3 and S4-10). Normalized fluorescent spectra obtained from a solution containing $3 \mu \mathrm{M}$ of Venus $+{ }^{\mathrm{C}} \mathrm{DD}_{\mathrm{BaeM}}$ mixed with an equivalent amount of its cognate construct, ${ }^{\mathrm{N}} \mathrm{DD}_{\mathrm{BaeN}}+\mathrm{mTurquoise} 2$, showed increased Venus fluorescence at $\sim 530$ $\mathrm{nm}$, and decreased mTurquoise 2 fluorescence at $\sim 480 \mathrm{~nm}$ in response to excitation at 420 $\mathrm{nm}$ compared to spectra obtained from solutions containing ${ }^{\mathrm{N}} \mathrm{DD}_{\mathrm{BaeN}}+\mathrm{mTurquoise} 2$ alone (processing and normalization are described in Figure S4). Conversely, fluorescence spectra obtained from combining noncognate constructs, such as Venus $+{ }^{C} \mathrm{DD}_{\text {BaeM }}$ with ${ }^{\mathrm{N}} \mathrm{DD}_{\text {DifG }}$ 
+ mTurquoise2, were similar to those obtained from solutions containing the ${ }^{\mathrm{N}} \mathrm{DD}$ + mTurquoise 2 construct alone (Figure $3 \mathrm{a}$ ). The extent of fluorescence increase at $\sim 530 \mathrm{~nm}$ and decrease at $\sim 480 \mathrm{~nm}$ is dependent on the Venus $+{ }^{\mathrm{C}} \mathrm{DD}$ concentration (Figures $3 \mathrm{~b}$ and S510). For each Venus $+{ }^{\mathrm{C}} \mathrm{DD} /{ }^{\mathrm{N}} \mathrm{DD}+\mathrm{mTurquoise} 2$ combination, containing $3 \mu \mathrm{M}$ of the ${ }^{\mathrm{N}} \mathrm{DD}$ + mTurquoise 2 construct, the $\sim 530 \mathrm{~nm}$ peak is evident at $\sim 1 \mu \mathrm{M}$ of the cognate Venus $+{ }^{\mathrm{C}} \mathrm{DD}$ and grows to the same height as the $\sim 480 \mathrm{~nm}$ peak at $\sim 6 \mu \mathrm{M}$ of the cognate Venus ${ }^{\mathrm{C}} \mathrm{DD}$. Noncognate Venus $+{ }^{\mathrm{C}} \mathrm{DD}$ constructs do not produce the $\sim 530 \mathrm{~nm}$ peak unless present at significantly higher concentrations (due to either lower-affinity interactions between the noncognate pairs or weak fluorescence from excess Venus $+{ }^{C}$ DD) (Figure 4).

Plotting FRET efficiency as a function of Venus+ ${ }^{\mathrm{C}} \mathrm{DD}$ concentration further indicated the orthogonality of cognate Venus $+{ }^{\mathrm{C}} \mathrm{DD}$ and ${ }^{\mathrm{N}} \mathrm{DD}+$ Turquoise 2 constructs. FRET efficiencies are most simply quantified as the ratio of the acceptor to either the donor or total fluorescence. ${ }^{25,26}$ However, accurate comparisons of such ratios generally require simple, often unimolecular, systems in which donor and acceptor concentrations remain constant. Bimolecular studies in which the concentrations of the donor or acceptor change have employed alternative methods. ${ }^{28-31}$ Here, a method ${ }^{25,29}$ was employed in which the FRET efficiency $\mathrm{E}$ at varying acceptor concentrations is quantified as

$$
E=1-\frac{F_{\mathrm{da}}}{F_{\mathrm{d}}}
$$

where the intensity of the donor emission is measured (at $480 \mathrm{~nm}$ ) in the absence $\left(F_{\mathrm{d}}\right)$ and presence $\left(F_{\mathrm{da}}\right)$ of an acceptor (Figure 5a). Plotting $\mathrm{E}$ as a function of acceptor concentration for each of the six combinations of matched Venus $+{ }^{\mathrm{C}} \mathrm{DD}$ and ${ }^{\mathrm{N}} \mathrm{DD}+\mathrm{mTurquoise} 2$ constructs shows that FRET efficiency increases with increasing acceptor concentration, and an analysis of all 36 combinations of Venus ${ }^{\mathrm{C}} \mathrm{DD}$ and ${ }^{\mathrm{N}} \mathrm{DD}+\mathrm{mTurquoise} 2$ constructs reveals sharper increases for matched pairs compared to mismatched pairs (Figures $5 \mathrm{~b}$ and S11).

Measurements of the FRET efficiency between Venus $+{ }^{\mathrm{C}} \mathrm{DD}$ and ${ }^{\mathrm{N}} \mathrm{DD}+\mathrm{mTurquoise} 2$ constructs as a function of Venus $+{ }^{\mathrm{C}} \mathrm{DD}$ concentration also enabled estimations of binding affinities. While the spectral overlap between Venus and mTurquoise2 precluded precise quantitation at concentrations of Venus $+{ }^{\mathrm{C}} \mathrm{DD}$ much higher than ${ }^{\mathrm{N}} \mathrm{DD}+\mathrm{mTurquoise} 2$ required for the accurate determination of affinities (Figure S12), ${ }^{32}$ the obtained data were fit to binding isotherms to estimate $K_{\mathrm{d}}$ values ${ }^{25,29}$

$$
E=E_{\max } x \frac{[\text { acceptor }]}{[\text { acceptor }]+K_{\mathrm{d}}}
$$

Fitting the FRET efficiency versus Venus ${ }^{\mathrm{C}} \mathrm{DD}$ concentration data to this equation yielded $K_{\mathrm{d}}$ values in the low micromolar range with acceptable $R^{2}$ values: Venus ${ }^{\mathrm{C}} \mathrm{DD}_{\mathrm{BaeM}} /$ ${ }^{\mathrm{N}} \mathrm{DD}_{\mathrm{BaeN}}+$ mTurquoise $2, K_{\mathrm{d}}=7.4 \pm 3.8 \mu \mathrm{M}, R^{2}=0.96$; Venus $+{ }^{\mathrm{C}^{2}} \mathrm{DD}_{\mathrm{DifF}} /{ }^{\mathrm{N}} \mathrm{DD}_{\mathrm{DifG}}$ + mTurquoise $2, K_{\mathrm{d}}=6.3 \pm 2.2 \mu \mathrm{M}, R^{2}=0.98$; Venus $+{ }^{\mathrm{C}} \mathrm{DD}_{\mathrm{MlnB}}{ }^{\mathrm{N}} \mathrm{DD}_{\mathrm{MlnC}}+$ mTurquoise $2, K_{\mathrm{d}}$ $=2.9 \pm 1.1 \mu \mathrm{M}, R^{2}=0.90 ;$ Venus $+{ }^{C_{D D}}{ }_{\mathrm{MlnC}}{ }^{\mathrm{N}} \mathrm{DD}_{\mathrm{MlnD}}+$ mTurquoise2, $K_{\mathrm{d}}=9.4 \pm 7.5 \mu \mathrm{M}$, $R^{2}=0.85$; Venus $+{ }^{\mathrm{C}} \mathrm{DD}_{\mathrm{MlnD}} /{ }^{\mathrm{N}} \mathrm{DD}_{\mathrm{MlnE}}+\mathrm{mTurquoise}, K_{\mathrm{d}}=4.8 \pm 2.3 \mu \mathrm{M}, R^{2}=0.73$; Venus ${ }_{+}^{\mathrm{C}} \mathrm{DD}_{\mathrm{MlnF}} /{ }^{\mathrm{N}} \mathrm{DD}_{\mathrm{MlnG}}+\mathrm{mTurquoise} 2, K_{\mathrm{d}}=14 \pm 7.8 \mu \mathrm{M}, R^{2}=0.84$ (Figure $5 \mathrm{c}$ and $5 \mathrm{~d}$ ). These values are similar to previously determined isothermal titration calorimetry measurements of 
the binding affinities of three of these cognate docking motifs in the context of their native polypeptides: ${ }^{\mathrm{C}} \mathrm{DD}_{\mathrm{MlnC}} /{ }^{\mathrm{N}} \mathrm{DD}_{\mathrm{MlnD}}, K_{\mathrm{d}}=1.8 \mu \mathrm{M} ;{ }^{\mathrm{C}} \mathrm{DD}_{\mathrm{MlnD}} /{ }^{\mathrm{N}} \mathrm{DD}_{\mathrm{MlnE}}, K_{\mathrm{d}}=0.8 \mu \mathrm{M}$; ${ }^{\mathrm{C}} \mathrm{DD}_{\mathrm{MlnF}}{ }^{\mathrm{N}} \mathrm{DD}_{\mathrm{MlnG}}, K_{\mathrm{d}}=9.0 \mu \mathrm{M} \cdot{ }^{13}$

Measurements were also made to determine whether salt concentration, $\mathrm{pH}$, or small impurities from the Ni-NTA purifications had a significant impact on Venus $+{ }^{\mathrm{C}} \mathrm{DD} / \mathrm{N} D \mathrm{D}$ + mTurquoise2 interactions. FRET titrations were conducted at 37.5, 75, 150, and $300 \mathrm{mM}$ $\mathrm{NaCl}$ for each combination of Venus $+{ }^{C} \mathrm{DD}_{\mathrm{BaeM}}$ and Venus $+{ }^{\mathrm{C}} \mathrm{DD}_{\mathrm{MlnF}}$ with ${ }^{\mathrm{N}} \mathrm{DD}_{\mathrm{BaeN}}$ + mTurquoise2 and ${ }^{\mathrm{N}} \mathrm{DD}_{\mathrm{MlnG}}+\mathrm{mTurquoise} 2$ (Figure S13). These titrations indicated similar orthogonality of the matched Venus $+{ }^{\mathrm{C}} \mathrm{DD} /{ }^{\mathrm{N}} \mathrm{DD}+\mathrm{mTurquoise} 2$ pairs, with similar $K_{\mathrm{d}}$ values for the matched pairs (Venus $+{ }^{C} \mathrm{DD}_{\mathrm{BaeM}} /{ }^{\mathrm{N}} \mathrm{DD}_{\mathrm{BaeN}}+$ mTurquoise2 and Venus $+{ }^{\mathrm{C}} \mathrm{DD}_{\mathrm{MlnF}} /$ ${ }^{\mathrm{N}} \mathrm{DD}_{\mathrm{MlnG}}+\mathrm{mT}$ urquoise2) at each salt concentration (Figure S14). FRET titrations also showed that the Venus $+{ }^{C} D_{\mathrm{BaeM}} /{ }^{\mathrm{N}} \mathrm{DD}_{\mathrm{BaeN}}+$ mTurquoise 2 and Venus ${ }^{\mathrm{C}}{ }_{\mathrm{DD}} \mathrm{MlnF} /{ }^{\mathrm{N}} \mathrm{DD}_{\mathrm{MlnG}}$ + mTurquoise2 pairs demonstrate specific, orthogonal binding from $\mathrm{pH} 6.0$ to 7.4 (Figure S15). Further purification of Ni-NTA-purified constructs by gel filtration chromatography did not result in significant changes in the measured FRET efficiencies (Figure S16).

Currently, the most utilized protein connectors are synthetic leucine-zipper coiled coils known as SYNZIP pairs. ${ }^{8,33,34}$ These can associate more tightly than the ${ }^{C}$ DD's and NDD's of four helix bundle docking motifs, often with low nanomolar affinities. However, the binding orientations and oligomerization states are not known for many of these pairs, and orthogonality is a concern when several are used in the same system. The structure of the four helix docking domain complex has been characterized (PDB Codes 2N5D and 5D2E), and its ${ }^{\mathrm{C}} \mathrm{DD}$ and ${ }^{\mathrm{N}} \mathrm{DD}$ components have been naturally selected for orthogonality within organisms such as B. amyloliquefaciens FZB42. ${ }^{12,13}$ The smaller size of the four helix bundle docking motifs, approximately half that of SYNZIP motifs, also confers an advantage in many applications.

Engineered macromolecular complexes are desired in diverse synthetic biotechnologies; however, general strategies for their construction remain elusive. Here, we demonstrate the use of four-helix bundle docking domains from trans-AT assembly lines to connect synthetic proteins with low micromolar binding constants. They may be used to daisy-chain enzymes in a designed biosynthetic pathway or to connect arrays of light harvesting or metal templated proteins. The small size, portability, and orthogonality of these docking motifs augurs well for their broad utility as molecular connectors to generate desired synthetic biomolecular assemblies.

\section{METHODS}

\section{Cloning and Protein Expression.}

The DNA encoding each docking domain was amplified from the genomic DNA of $B$. amyloliquefaciens FZB42, and the genes encoding the GFP variants Venus and mTurquoise2 (F46L/F64L/S65G/V68L/S72A/D133G/M153T/V163A/S175G/T203Y and F64L/Y66W/ S72A/N146F/H148D/M153T/V163A/S175G/A206K/H231L) were amplified from the YTK kit plasmids pYTK033 and pYTK057, respectively (Table S1). Amplicons were gel extracted and Gibson assembled into the pET28b expression vector (New England Biolabs) 
such that the hexahistidine tag is encoded opposite the docking domain. pET28b was digested with NdeI and XhoI to assemble Venus ${ }^{\mathrm{C}} \mathrm{DD}$ constructs and NcoI and XhoI to assemble ${ }^{\mathrm{N}} \mathrm{DD}+\mathrm{mTurquoise} 2$ constructs. The histidine-tagged fusion proteins were expressed in E. coli BL21(DE3) (6 L of LB media) that were grown to an $\mathrm{OD}_{600}$ of 0.6 at 37 ${ }^{\circ} \mathrm{C}$, induced with $0.5 \mathrm{mM}$ isopropyl $\beta$-D-1-thiogalactopyranoside, and left overnight at $15{ }^{\circ} \mathrm{C}$ for ${ }^{\mathrm{N}} \mathrm{DD}+\mathrm{mTurquoise} 2$ constructs or $5 \mathrm{~h}$ at $37{ }^{\circ} \mathrm{C}$ for Venus+ ${ }^{\mathrm{C}} \mathrm{DD}$ constructs. Protein was purified from cell lysate using HisPur nickel-NTA resin (Thermo Scientific), flash frozen, and stored at $-80{ }^{\circ} \mathrm{C}$. Additional preparations of Venus $+{ }^{C} D_{\text {BaeM }},{ }^{N} D_{B a e N}+$ mTurquoise2, Venus+ ${ }^{\mathrm{C}} \mathrm{DD}_{\mathrm{MlnF}}$, and ${ }^{\mathrm{N}} \mathrm{DD}_{\mathrm{MlnG}}+\mathrm{mTurquoise} 2$ were polished via gel filtration for salt- and pH-dependent FRET assays (GE Superdex 200 Increase 10/300 column equilibrated in 150 $\mathrm{mM} \mathrm{NaCl}, 10 \mathrm{mM}$ HEPES $\mathrm{pH} 7.5$, and 10\% (v/v) glycerol).

\section{Size-Exclusion Chromatography Docking Assays.}

Pairs of Venus $+{ }^{\mathrm{C}} \mathrm{DD}$ and ${ }^{\mathrm{N}} \mathrm{DD}+\mathrm{mTurquoise} 2$ constructs were combined $\sim 1: 1(75 \mu \mathrm{M}$ for each protein) in a $1 \mathrm{~mL}$ volume and injected onto a Superdex 200 Increase gel filtration column (GE Healthcare Life Sciences) equilibrated with $150 \mathrm{mM} \mathrm{NaCl}, 15 \mathrm{mM}$ HEPES (pH 7.5). Protein elution was monitored by absorbance at $280 \mathrm{~nm}$, and fractions were collected every $0.5 \mathrm{~mL}$ after $9.5 \mathrm{~mL}$ had eluted. Individual domains were also run ( $75 \mu \mathrm{M}$ in $1 \mathrm{~mL})$. Fractions 12-23 from each run were analyzed with Coomassie-stained SDSPAGE gels loaded with $15 \mu \mathrm{L}$ of each fraction.

\section{FRET Measurements.}

Fluorescence measurements were conducted in a solution containing $75 \mathrm{mM} \mathrm{NaCl}$ and 25 $\mathrm{mM} \mathrm{NaPO}_{4}(\mathrm{pH} 7.4)$ in all experiments, except where noted, and in a clear bottom 96-well plate. Fluorescence spectra were recorded between 460 and $600 \mathrm{~nm}$ (420 nm excitation, 5 $\mathrm{nm}$ intervals, $\sim 25^{\circ} \mathrm{C}$ ). To obtain a titration curve, a Venus $+{ }^{\mathrm{C}} \mathrm{DD}$ construct was successively added to solutions initially containing $3 \mu \mathrm{M}$ of ${ }^{\mathrm{N}} \mathrm{DD}+\mathrm{mTurquoise} 2$ constructs and $220 \mu \mathrm{L}$ total volume. Spectra taken at each concentration of the Venus $+{ }^{\mathrm{C}} \mathrm{DD}$ construct were normalized by multiplying the ratio of current to starting volume to correct for dilution of the ${ }^{\mathrm{N}} \mathrm{DD}+\mathrm{mTurquoise} 2$ construct and subtracting a spectrum of a sample containing no ${ }^{\mathrm{N}} \mathrm{DD}$ +Turquoise 2 construct but an equivalent amount of the Venus+ ${ }^{\mathrm{C}} \mathrm{DD}$ construct in response to $420 \mathrm{~nm}$ excitation. To correct for signal decrease over time due to changes in solution refractive index due to increasing protein concentration, spectra were further normalized by dividing the fluorescence at each point by the sum of the fluorescence values taken between 470 and $540 \mathrm{~nm}$. To estimate affinities, the normalized estimated FRET efficiencies were plotted as a function of Venus $+{ }^{\mathrm{C}} \mathrm{DD}$ concentration in GraphPad Prism and fit to the standard single-site binding isotherm to yield $E_{\max }$ and $K_{\mathrm{d}}$ values.

\section{Supplementary Material}

Refer to Web version on PubMed Central for supplementary material. 


\section{ACKNOWLEDGMENTS}

Research was supported by the National Institutes of Health (GM106112 to A.T.K.), the Welch Foundation (F-1712 to A.T.K.), the US Army Research Laboratory and the US Army Research Office (W911NF-1-51-0120 to A.D.E.), and an Arnold O. Beckman Postdoctoral Fellowship held by A.J.S.

\section{REFERENCES}

(1). Arai R (2018) Hierarchical design of artificial proteins and complexes toward synthetic structural biology. Biophys. Rev 10, 391-410. [PubMed: 29243094]

(2). Julin S, Nummelin S, Kostiainen MA, and Linko V (2018) DNA nanostructure-directed assembly of metal nanoparticle superlattices. J. Nanopart. Res 20, 119. [PubMed: 29950921]

(3). Mohammed AM, Sulc P, Zenk J, and Schulman R (2017) Self-assembling DNA nanotubes to connect molecular landmarks. Nat. Nanotechnol 12, 312-316. [PubMed: 27992412]

(4). Praetorius F, and Dietz H (2017) Self-assembly of genetically encoded DNA-protein hybrid nanoscale shapes. Science 355, eaam5488. [PubMed: 28336611]

(5). Bailey JB, Subramanian RH, Churchfield LA, and Tezcan FA (2016) Metal-Directed Design of Supramolecular Protein Assemblies. Methods Enzymol. 580, 223-250. [PubMed: 27586336]

(6). Priemel T, Degtyar E, Dean MN, and Harrington MJ (2017) Rapid self-assembly of complex biomolecular architectures during mussel byssus biofabrication. Nat. Commun 8, 14539. [PubMed: 28262668]

(7). Alberstein R, Suzuki Y, Paesani F, and Tezcan FA (2018) Engineering the entropy-driven freeenergy landscape of a dynamic nanoporous protein assembly. Nat. Chem 10, 732-739. [PubMed: 29713036]

(8). Reinke AW, Grant RA, and Keating AE (2010) A Synthetic Coiled-Coil Interactome Provides Heterospecific Modules for Molecular Engineering. J. Am. Chem. Soc 132, 6025-6031. [PubMed: 20387835]

(9). Jang Y, Choi WT, Heller WT, Ke Z, Wright ER, and Champion JA (2017) Engineering Globular Protein Vesicles through Tunable Self-Assembly of Recombinant Fusion Proteins. Small 13, 1700399.

(10). Piel J (2002) A polyketide synthase-peptide synthetase gene cluster from an uncultured bacterial symbiont of Paederus beetles. Proc. Natl. Acad. Sci. U. S. A 99, 14002-14007. [PubMed: 12381784]

(11). Cheng YQ, Tang GL, and Shen B (2003) Type I polyketide synthase requiring a discrete acyltransferase for polyketide biosynthesis. Proc. Natl. Acad. Sci. U. S. A 100, 3149-3154. [PubMed: 12598647]

(12). Dorival J, Annaval T, Risser F, Collin S, Roblin P, Jacob C, Gruez A, Chagot B, and Weissman KJ (2016) Characterization of Intersubunit Communication in the Virginiamycin transAcyl Transferase Polyketide Synthase. J. Am. Chem. Soc 138, 4155-4167. [PubMed: 26982529]

(13). Zeng J, Wagner DT, Zhang Z, Moretto L, Addison JD, and Keatinge-Clay AT (2016) Portability and Structure of the Four-Helix Bundle Docking Domains of trans-Acyltransferase Modular Polyketide Synthases. ACS Chem. Biol 11, 2466-2474. [PubMed: 27362945]

(14). Piel J (2010) Biosynthesis of polyketides by trans-AT polyketide synthases. Nat. Prod. Rep 27, 996-1047. [PubMed: 20464003]

(15). Helfrich EJ, and Piel J (2016) Biosynthesis of polyketides by trans-AT polyketide synthases. Nat. Prod. Rep 33, 231-316. [PubMed: 26689670]

(16). Keatinge-Clay AT (2012) The structures of type I polyketide synthases. Nat. Prod. Rep 29, 10501073. [PubMed: 22858605]

(17). Keatinge-Clay AT (2017) The Uncommon Enzymology of Cis-Acyltransferase Assembly Lines. Chem. Rev 117, 5334-5366. [PubMed: 28394118]

(18). Wakimoto T, Egami Y, Nakashima Y, Wakimoto Y, Mori T, Awakawa T, Ito T, Kenmoku H, Asakawa Y, Piel J, and Abe I (2014) Calyculin biogenesis from a pyrophosphate protoxin produced by a sponge symbiont. Nat. Chem. Biol 10, 648-U193. [PubMed: 24974231] 
(19). Khosla C, Tang Y, Chen AY, Schnarr NA, and Cane DE (2007) Structure and mechanism of the 6-deoxyerythronolide B synthase. Annu. Rev. Biochem 76, 195-221. [PubMed: 17328673]

(20). Weissman KJ (2006) The structural basis for docking in modular polyketide biosynthesis. ChemBioChem 7, 485-494. [PubMed: 16470766]

(21). Gokhale RS, Tsuji SY, Cane DE, and Khosla C (1999) Dissecting and exploiting intermodular communication in polyketide synthases. Science 284, 482-485. [PubMed: 10205055]

(22). Whicher JR, Smaga SS, Hansen DA, Brown WC, Gerwick WH, Sherman DH, and Smith JL (2013) Cyanobacterial polyketide synthase docking domains: a tool for engineering natural product biosynthesis. Chem. Biol 20, 1340-1351. [PubMed: 24183970]

(23). Nagai T, Ibata K, Park ES, Kubota M, Mikoshiba K, and Miyawaki A (2002) A variant of yellow fluorescent protein with fast and efficient maturation for cell-biological applications. Nat. Biotechnol 20, 87-90. [PubMed: 11753368]

(24). Goedhart J, van Weeren L, Hink MA, Vischer NOE, Jalink K, and Gadella TWJ (2010) Bright cyan fluorescent protein variants identified by fluorescence lifetime screening. Nat. Methods 7 , 137-U174. [PubMed: 20081836]

(25). Miyawaki A (2011) Development of probes for cellular functions using fluorescent proteins and fluorescence resonance energy transfer. Annu. Rev. Biochem 80, 357-373. [PubMed: 21529159]

(26). Bajar BT, Wang ES, Zhang S, Lin MZ, and Chu J (2016) A Guide to Fluorescent Protein FRET Pairs. Sensors 16, 1488.

(27). Erard M, Fredj A, Pasquier H, Beltolngar DB, Bousmah Y, Derrien V, Vincent P, and Merola F (2013) Minimum set of mutations needed to optimize cyan fluorescent proteins for live cell imaging. Mol. BioSyst 9, 258-267. [PubMed: 23192565]

(28). Song Y, Madahar V, and Liao J (2011) Development of FRET assay into quantitative and highthroughput screening technology platforms for protein-protein interactions. Ann. Biomed. Eng 39, 1224-1234. [PubMed: 21174150]

(29). Wei ZH, Chen H, Zhang C, and Ye BC (2014) FRET-based system for probing protein-protein interactions between sigmaR and RsrA from Streptomyces coelicolor in response to the redox environment. PLoS One 9, No. e92330. [PubMed: 24651617]

(30). Palomba F, Genovese D, Petrizza L, Rampazzo E, Zaccheroni N, and Prodi L (2018) Mapping heterogeneous polarity in multicompartment nanoparticles. Sci. Rep 8, 17095. [PubMed: 30459427]

(31). Jiang L, Xiong Z, Song Y, Lu Y, Chen Y, Schultz JS, Li J, and Liao J (2019) Protein-Protein Affinity Determination by Quantitative FRET Quenching. Sci. Rep 9, 2050. [PubMed: 30765720]

(32). Hulme EC, and Trevethick MA (2010) Ligand binding assays at equilibrium: validation and interpretation. Br. J. Pharmacol 161, 1219-1237. [PubMed: 20132208]

(33). Grigoryan G, Reinke AW, and Keating AE (2009) Design of protein-interaction specificity gives selective bZIP-binding peptides. Nature 458, 859-864. [PubMed: 19370028]

(34). Thompson KE, Bashor CJ, Lim WA, and Keating AE (2012) SYNZIP protein interaction toolbox: in vitro and in vivo specifications of heterospecific coiled-coil interaction domains. ACS Synth. Biol 1, 118-129. [PubMed: 22558529] 
A cis-AT assembly lines

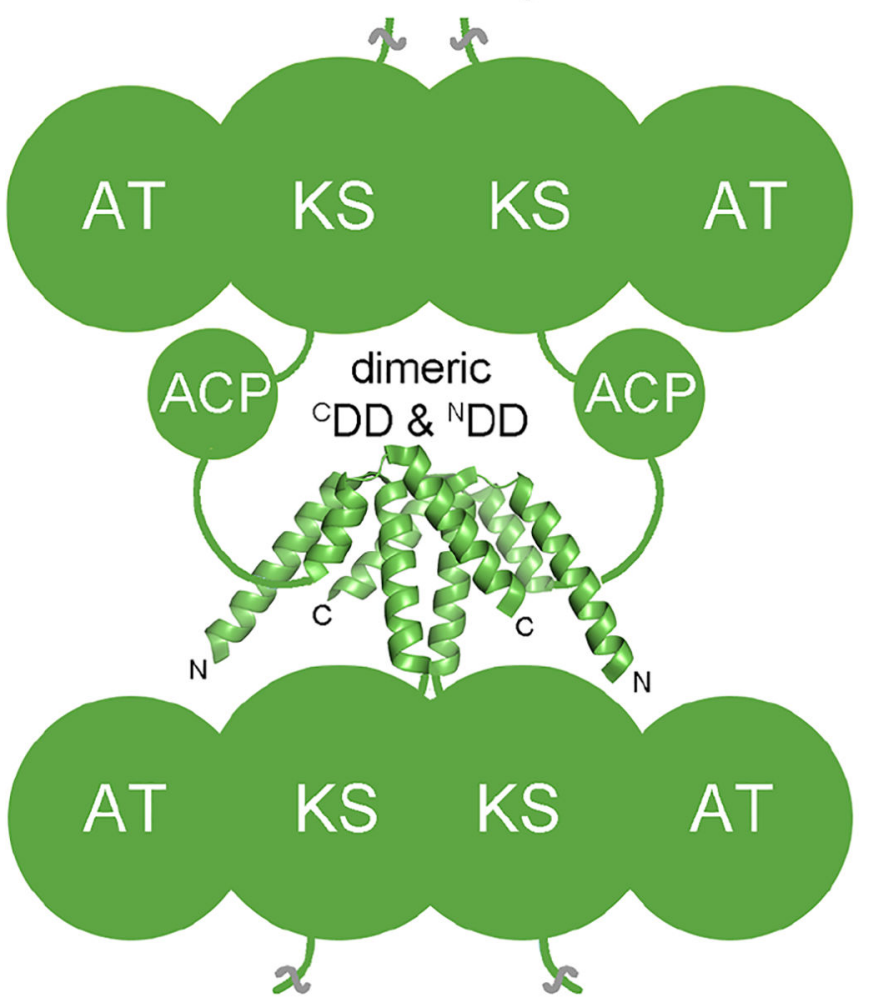

trans-AT assembly lines

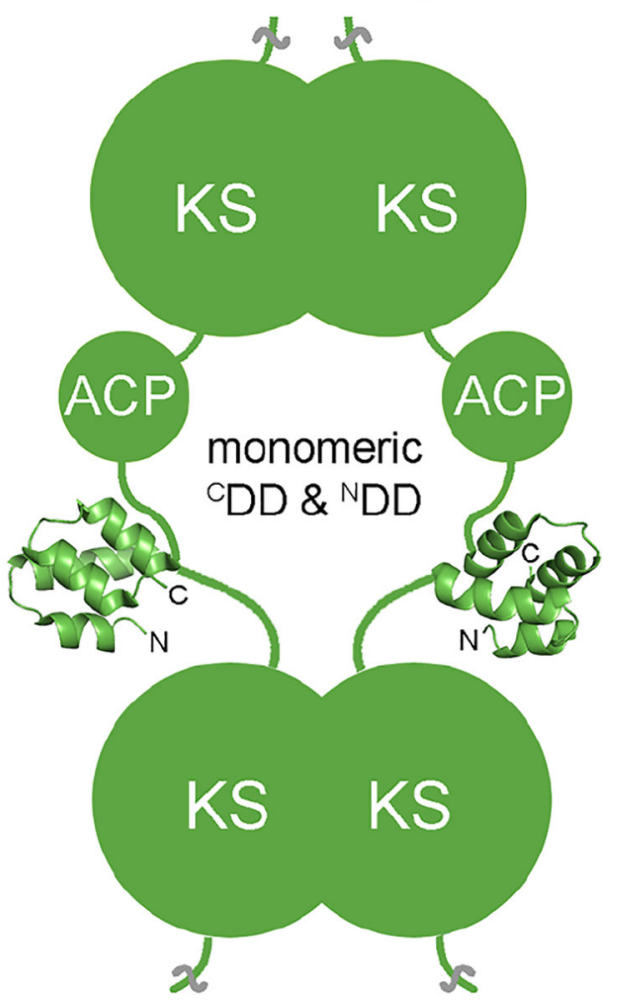

B

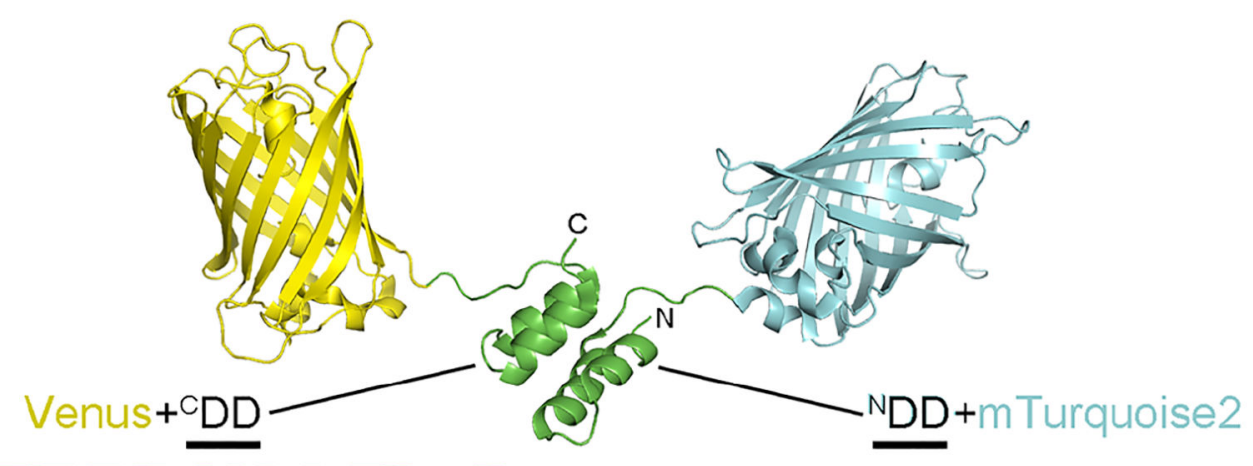

BaeM EYTDQEI IAMMKOVSEGTLDFKRVQDIIEGSKTYES

DifF TSPLETYERLLDELEKNEISIEAAVKRTIGFYRD

MInB KNEDQEILFLLEQLKNGELSADQVYQLLEGK

MInC GKNERVKELLROLKAGELTAEEADYALERMOD

MInD DTADGEIMSLLEKAQTGEMNTKETSELIEELLFHE

MInF VQTDDELIRLLRQLETNDIDQKAVLKQLMGEE

1

25

MNHKELLDAYRSGTLTIAEVEQKLQAFKRTTA BaeN MKEFLHRVFSDVKNKKMTKQDAIGILRDYDMRM- DifG

MOIKOILSLIEEQQMSPDAGLELIRTYRKEQM MInC MKEARHIRKKVLSDIESGIISLEEGVKRIOOLGSHS- MInD MNEKTMQIEOIVKKVKECSLTPEEGLELIKSLGKTH- MInE MNEKTMQIEQIVKKVKECSLTPEEGLELIKSLGKTH- MInE
MNGKREQLSDILDQIQTGQMSADEGYARVTSIQNQKS MInG 1

25

Figure 1.

Co-opting docking domains from biosynthetic assembly lines. (A) A comparison of enzymatic assembly line docking domains (PDB IDs 4MYY, 2N5D) shows that, while cisAT assembly line docking domains (class 2 shown, but class 1 is also dimeric) ${ }^{22}$ are obligate dimers, trans-AT assembly line docking domains are not and could be useful in complexing proteins of various oligomerizaton states. KS, ketosynthase; AT, acyltransferase; ACP, acyl carrier protein. (B) C- and N-terminal docking domain ( ${ }^{\mathrm{C}} \mathrm{DD}$ and ${ }^{\mathrm{N}} \mathrm{DD}$ ) motifs were appended to the C-terminus of Venus and the N-terminus of mTurquoise2. The sequences of the six pairs used in this study from the bacillaene (Bae), difficidin (Dif), and macrolactin 
(Mln) assembly lines are displayed along with their numbering. ${ }^{13}$ BaeM/BaeN, bacillaene, Bacillus amyloliquefaciens, CAG23959/CAG23960; DifF/DifG, difficidin, Bacillus amyloliquefaciens, CAG23977/CAG23978; MlnB/MlnC/MlnD/MlnE/MlnF/MlnG, macrolactin, Bacillus amyloliquefaciens, CAG23964/CAG23965/CAG23966/CAG23967/ CAG23968/CAG23969. 
A

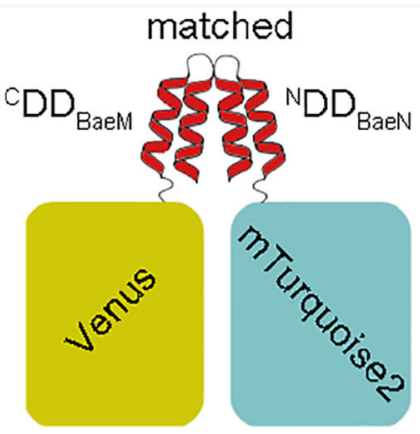

B

mis-

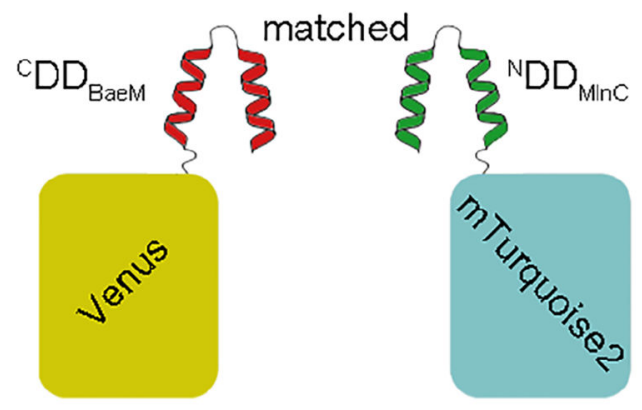

Size-exclusion chromatography

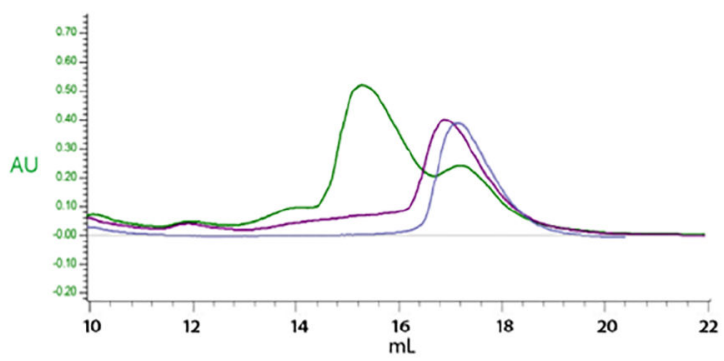

Venus $+{ }^{\mathrm{C} D D} \quad \mathrm{NDD}+\mathrm{m}$ Turquoise2

Venus $+{ }^{\complement} D D$ \& NDD+mTurquoise2

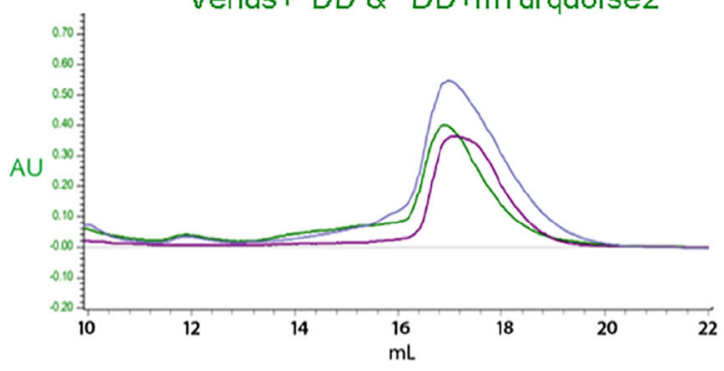

C

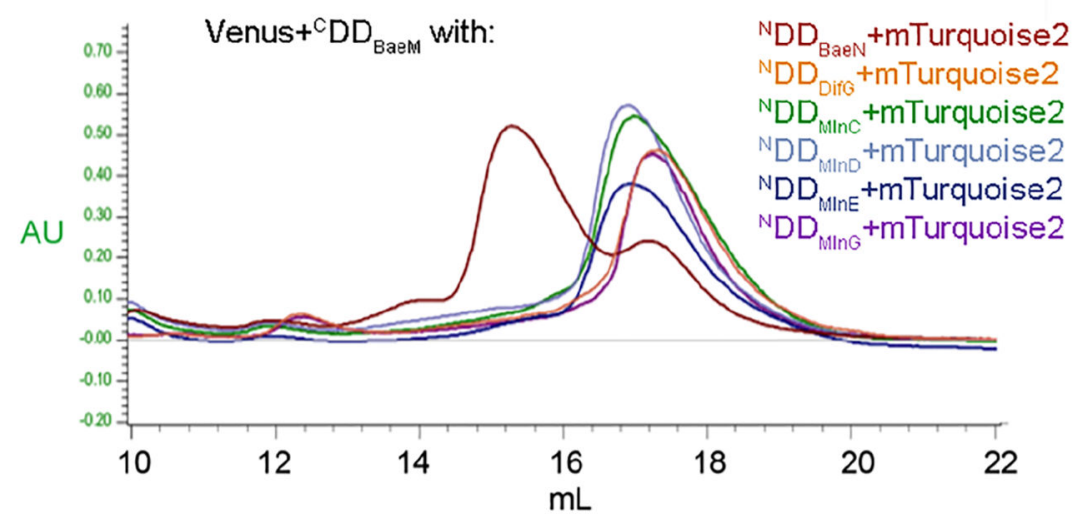

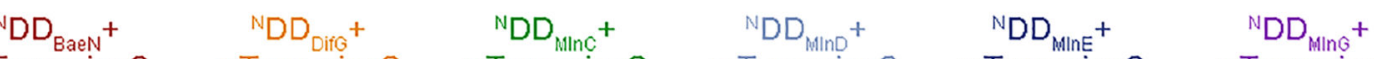
mTurquoise2 mTurquoise2 mTurquoise2 mTurquoise2 mTurquoise2 mTurquoise2

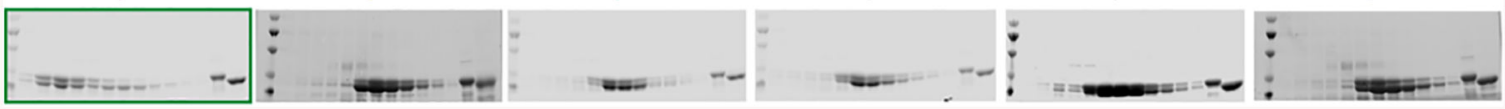

Figure 2.

Size-exclusion chromatography docking assay. Data for Venus ${ }^{\mathrm{C}}{ }^{\mathrm{DD}} \mathrm{D}_{\mathrm{BaeM}}$ are shown here (data for all Venus $+{ }^{\mathrm{C}}$ DD constructs are reported in Figures S2 and S3). (A) Individually, the cognate constructs Venus $+{ }^{C} D_{\mathrm{BaeM}}$ and ${ }^{\mathrm{N}} \mathrm{DD}_{\mathrm{BaeN}}+\mathrm{mTurquoise} 2$ elute at $17 \mathrm{~mL}$. A coinjection results in a species that elutes at $15 \mathrm{~mL}$. (B) A coinjection of the noncognate constructs Venus $+{ }^{C} D_{B a e M}$ and ${ }^{{ }^{N}} D_{M l n C}+$ mTurquoise 2 does not generate an earliereluting species. (C) Venus ${ }^{C}{ }^{C} D_{B a e M}$ paired with each of the ${ }^{\mathrm{N}} \mathrm{DD}+\mathrm{mTurquoise} 2$ constructs shows that only the coinjection with ${ }^{{ }^{N}} D_{B a e N}+$ mTurquoise 2 results in complex formation

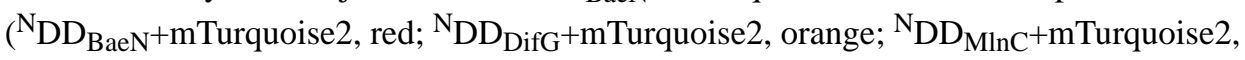

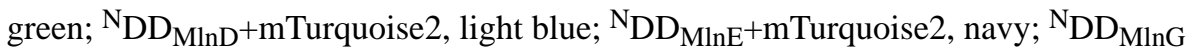


+ mTurquoise2, purple). Coomassie-stained SDS-PAGE gels confirm that both the Venus $+{ }^{\mathrm{C}} \mathrm{DD}_{\mathrm{BaeM}}$ and ${ }^{\mathrm{N}} \mathrm{DD}_{\mathrm{BaeN}}+\mathrm{m}$ Turquoise 2 constructs are present in the early eluting species (boxed in green). Legend for all SDS-PAGE gels: Lane 1, ladder (PageRuler Prestained Protein, Thermo Scientific); lanes 2-13, fractions $12-23$; lane 14 , Venus $+{ }^{\mathrm{C}} \mathrm{DD}$ construct; lane $15,{ }^{\mathrm{N}} \mathrm{DD}+\mathrm{mTurquoise} 2$ construct. Matched ${ }^{\mathrm{N}} \mathrm{DD}_{\mathrm{BaeN}}+\mathrm{mTurquoise} 2$ and Venus ${ }^{\mathrm{C}} \mathrm{DD}_{\mathrm{BaeM}}$ appear in lanes 3-5 (corresponding to fractions $13-15$ ), while mismatched constructs do not. 
A

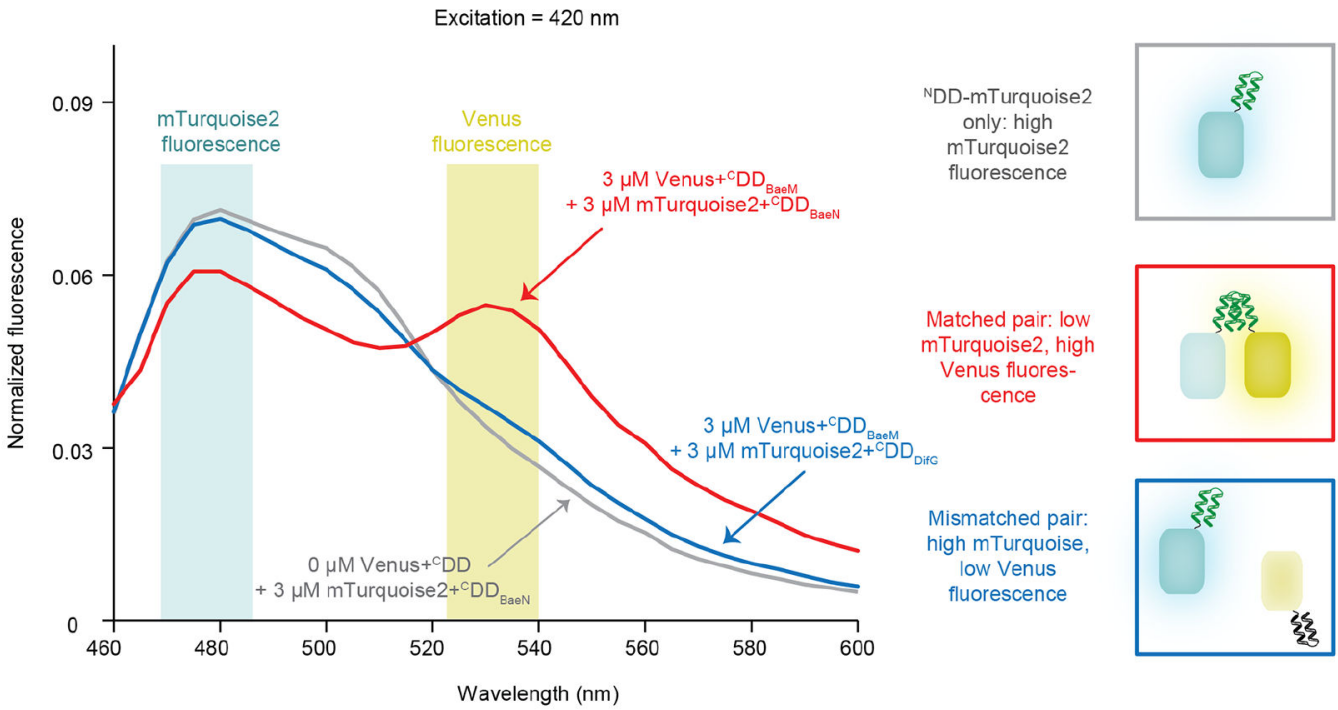

B
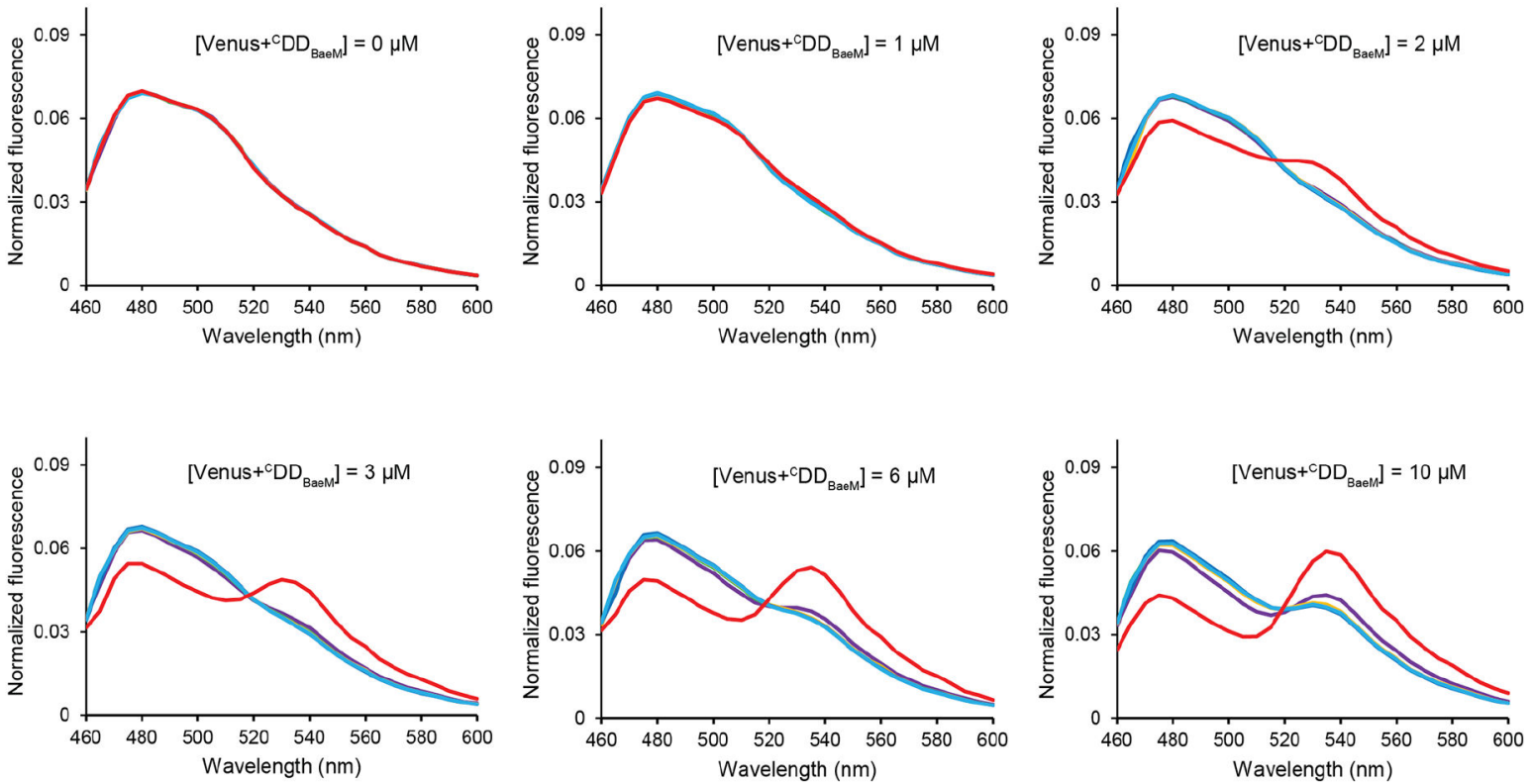

Figure 3.

FRET from complexes. (A) Emission spectra of an ${ }^{\mathrm{N}} \mathrm{DD}+\mathrm{mTurquoise} 2$ construct alone (gray), an equimolar matched Venus $+{ }^{\mathrm{C}} \mathrm{DD} /{ }^{\mathrm{N}} \mathrm{DD}+\mathrm{mTurquoise} 2$ pair (red), and an equimolar unmatched Venus $+{ }^{\mathrm{C}} \mathrm{DD} /{ }^{\mathrm{N}} \mathrm{DD}+\mathrm{mTurquoise} 2$ pair (blue) in response to direct excitation of ${ }^{\mathrm{N}}$ DD+mTurquoise 2 at $420 \mathrm{~nm}$. While excitation of an ${ }^{\mathrm{N}} \mathrm{DD}+\mathrm{mTurquoise} 2$ construct alone and in solution with an unmatched Venus ${ }^{\mathrm{C}} \mathrm{DD}$ construct produces a single peak at $\sim 480$ $\mathrm{nm}$, excitation of a matched Venus $+{ }^{\mathrm{C}} \mathrm{DD} /{ }^{\mathrm{N}} \mathrm{DD}+$ mTurquoise 2 pair produces a second emission peak at $\sim 530 \mathrm{~nm}$. (B) Emission spectra of increasing concentrations of Venus ${ }^{\mathrm{C}} \mathrm{DD}_{\mathrm{BaeM}}$ with $3 \mu \mathrm{M}$ of each ${ }^{\mathrm{N}} \mathrm{DD}+\mathrm{mT}$ urquoise2 variant in response to $420 \mathrm{~nm}$ excitation. Increasing concentrations of Venus $+{ }^{\mathrm{C}} \mathrm{DD}_{\mathrm{BaeM}}$ in the presence of its cognate, ${ }^{\mathrm{N}} \mathrm{DD}_{\mathrm{BaeN}}$ + mTurquoise2 (red), produces decreased donor and increased acceptor fluorescence. Increasing concentrations of Venus $+{ }^{C} D_{B} D_{B a e}$ in the presence of noncognate ${ }^{\mathrm{N}} \mathrm{DD}$ + mTurquoise 2 proteins produce little effect until $10 \mu \mathrm{M}$, when acceptor fluorescence 
increases due to low-affinity interactions between mismatched ${ }^{\mathrm{C}} \mathrm{DD} / \mathrm{N} D \mathrm{DD}$ pairs or due to offmaximum excitation becoming too large to accurately subtract. ${ }^{\mathrm{N}} \mathrm{DD}_{\mathrm{BaeN}}+\mathrm{mTurquoise} 2$, red; ${ }^{N} D_{\text {DifG }}+m$ Turquoise2, orange; ${ }^{N} D_{M l n C}+m$ Turquoise2, green; ${ }^{N} D_{M l n D}$ +mTurquoise2, light blue; ${ }^{\mathrm{N}} \mathrm{DD}_{\mathrm{MlnE}}+\mathrm{mTurquoise} 2$, blue; ${ }^{\mathrm{N}} \mathrm{DD}_{\mathrm{MlnG}}+\mathrm{mTurquoise}$ 2, purple. Because the spectra of the mismatched pairs are extremely similar, the ${ }^{\mathrm{N}} \mathrm{DD}_{\mathrm{DifG}}$ +mTurquoise2 (orange), ${ }^{\mathrm{N}} \mathrm{DD}_{\mathrm{MlnC}}+\mathrm{mTurquoise} 2$ (green), and $\mathrm{DD}_{\mathrm{MlnE}}+\mathrm{m}$ Turquoise2 (dark blue) spectra are mostly obscured. 
A

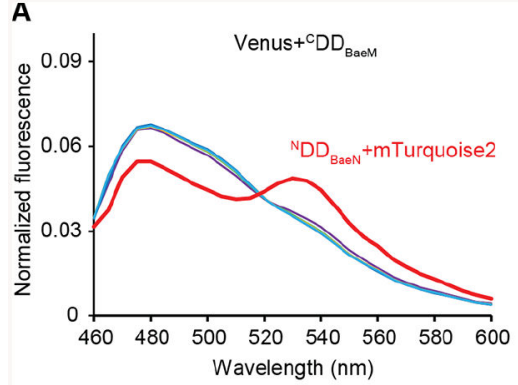

D

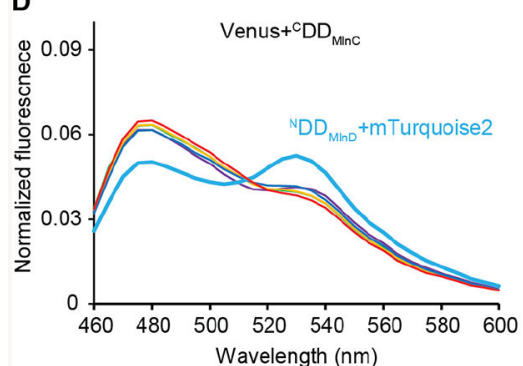

B

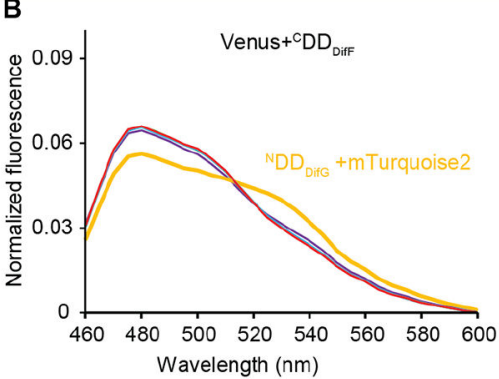

$\mathbf{E}$

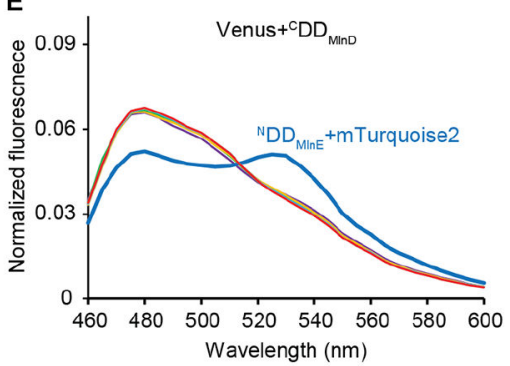

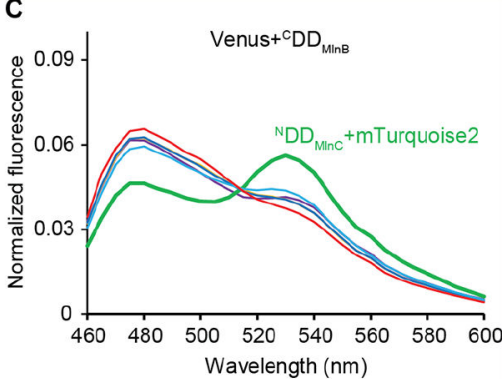

$\mathbf{F}$

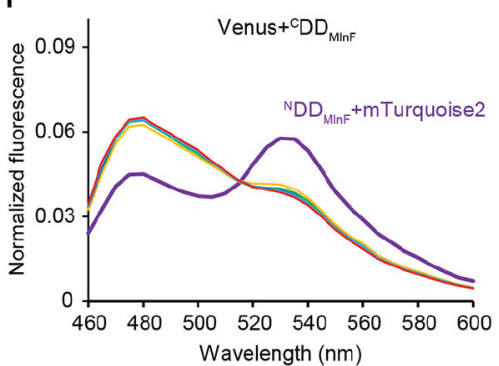

Figure 4.

Emission spectra of $3 \mu \mathrm{M}$ of each Venus+ ${ }^{C} \mathrm{DD}$ with $3 \mu \mathrm{M}$ of each mTurquoise $+{ }^{\mathrm{N}} \mathrm{DD}$.

Thicker traces correspond to matched pairs. While matched pairs produce decreased donor fluorescence $(480 \mathrm{~nm})$ and increased acceptor fluorescence $(530 \mathrm{~nm})$, mismatched pairs do not. ${ }^{\mathrm{N}} \mathrm{DD}_{\mathrm{BaeN}}+\mathrm{mT}$ Turquoise2, red; ${ }^{\mathrm{N}} \mathrm{DD}_{\mathrm{DifG}}+\mathrm{mT}$ Turquoise2, orange; ${ }^{{ }^{2}} \mathrm{DD}_{\mathrm{MlnC}}+\mathrm{mTurquoise} 2$, green; ${ }^{\mathrm{N}_{\mathrm{DD}}} \mathrm{MlnD}^{+m}$ Turquoise2, light blue; ${ }^{\mathrm{N}} \mathrm{DD}_{\mathrm{MlnE}}+\mathrm{mT}$ Trquoise 2, blue; ${ }^{\mathrm{N}} \mathrm{DD}_{\mathrm{MlnG}}$ +mTurquoise2, purple. 
A

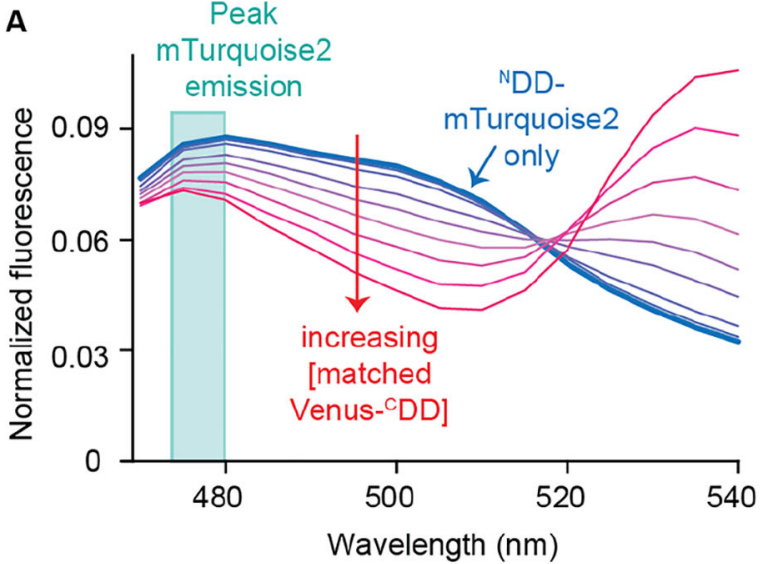

C

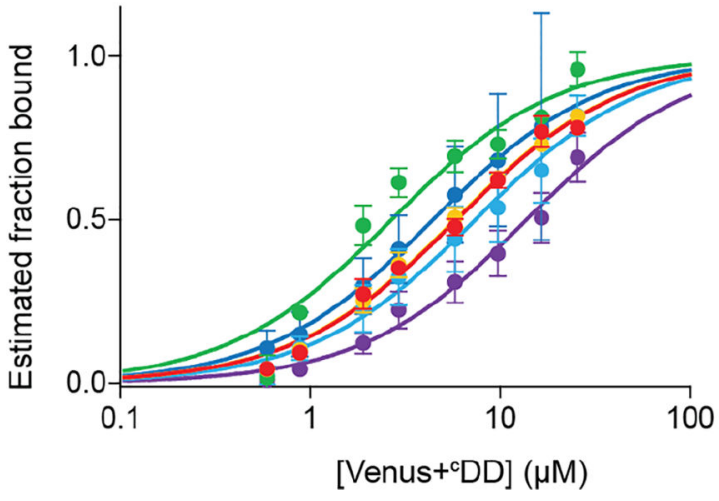

B

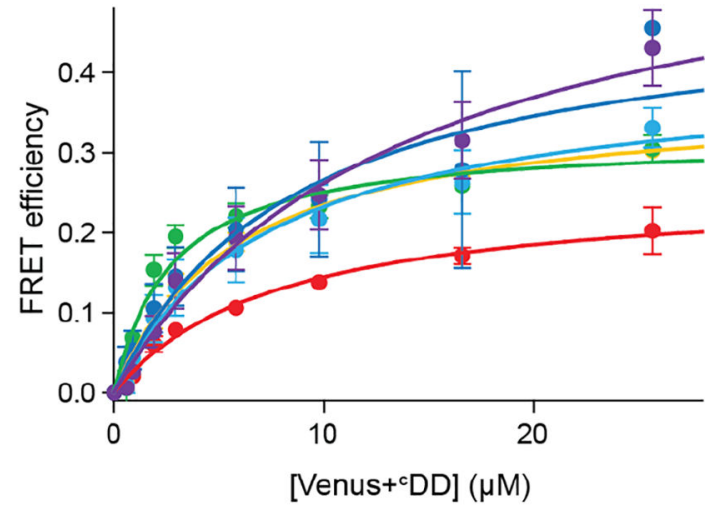

D

\begin{tabular}{|c|c|c|}
\hline Matched pair & Est. $K_{d}(\mu \mathrm{M})$ & $\mathrm{R}^{2}$ \\
\hline${ }^{C} \mathrm{DD}_{\text {Bae M }}{ }^{\mathrm{N}} \mathrm{DD}_{\text {BaeN }}$ & $7.4 \pm 3.8$ & 0.96 \\
\hline${ }^{C} D D_{\text {DifF }}{ }^{N} D D_{\text {DifG }}$ & $6.3 \pm 2.2$ & 0.98 \\
\hline${ }^{\mathrm{C}} \mathrm{DD}_{\mathrm{MnB}}{ }^{\mathrm{N}} \mathrm{DD}_{\mathrm{MnC}}$ & $2.9 \pm 1.1$ & 0.90 \\
\hline${ }^{\mathrm{C}} \mathrm{DD} \mathrm{MnC}_{\mathrm{Mn}} /{ }^{\mathrm{N}} \mathrm{DD} \mathrm{D}_{\mathrm{MnD}}$ & $9.4 \pm 7.5$ & 0.85 \\
\hline${ }^{\mathrm{C}} \mathrm{DD}_{\mathrm{MnD}} /{ }^{\mathrm{N}} \mathrm{DD} \mathrm{M}_{\mathrm{MnE}}$ & $4.8 \pm 2.3$ & 0.73 \\
\hline${ }^{\mathrm{C}} \mathrm{DD}_{\mathrm{MnF}} /{ }^{\mathrm{N}} \mathrm{DL}$ & $14 \pm 7.8$ & 0.84 \\
\hline
\end{tabular}

Figure 5.

Estimating binding constants from the titration curves of matched pairs. (A) Plot showing normalized fluorescence curves obtained from titrating an increasing amount of Venus+ ${ }^{\mathrm{C}} \mathrm{DD}$ to its cognate ${ }^{\mathrm{N}} \mathrm{DD}+\mathrm{m}$ Turquoise2. The trace obtained from ${ }^{\mathrm{N}} \mathrm{DD}+\mathrm{mT}$ Trquoise2 is shown as the thick blue line; traces obtained with increasing Venus $+{ }^{\mathrm{C}} \mathrm{DD}$ concentration are shown as thinner purple to red lines. The turquoise box outlines the peak ${ }^{\mathrm{N}} \mathrm{DD}+\mathrm{mT}$ Turquoise 2 (donor) fluorescence at $475-480 \mathrm{~nm}$. (B) Plots of the FRET efficiency E by Venus+ ${ }^{\mathrm{C}} \mathrm{DD}$ concentration for all matched pairs. Each color corresponds to a different matched pair: Venus $+{ }^{C} D_{\text {BaeM }} /{ }^{N} D_{\mathrm{BaN}}+$ mTurquoise2, red; Venus $+{ }^{C} D_{\text {DifF }} /{ }^{N} D_{\text {DifG }}+$ mTurquoise2, orange; Venus $+{ }^{C} D_{M l n B} /{ }^{N} D_{M l n C}+$ mTurquoise2, green; Venus $+{ }^{C} D_{\mathrm{DlnC}^{\prime}}{ }^{\mathrm{N}} \mathrm{DD}_{\mathrm{MlnD}}$ + mTurquoise2, light blue; Venus $+{ }^{C} \mathrm{DD}_{\mathrm{MlnD}} /{ }^{\mathrm{N}} \mathrm{DD}_{\mathrm{MlnE}}+\mathrm{mTurquoise} 2$, blue; Venus ${ }_{+}{ }^{\mathrm{C}} \mathrm{DD}_{\mathrm{MlnF}}{ }^{\mathrm{N}} \mathrm{DD}_{\mathrm{MlnG}}+\mathrm{m}$ Turquoise2, purple. The data were fit well by a single-site binding curve function, as shown by the solid lines. Each point is the average of three replicates. Error bars correspond to standard deviations. (C) Plots of estimated fraction of ${ }^{\mathrm{N}} \mathrm{DD}$ + mTurquoise 2 bound at each Venus $+{ }^{\mathrm{C}}$ DD concentration using the data shown in panel B. (D) Estimated dissociation constant $\left(K_{\mathrm{d}}\right)$ values of matched pairs and $R^{2}$ of fit to eq 3 . Standard deviations are indicated. 